\title{
Systematic Ranking of Nucleophiles as Electron Donors
}

\author{
Kim Daasbjerg, ${ }^{*}$ Stig R. Knudsen, Katrine N. Sonnichsen, Adalgisa R. Andrade and \\ Steen U. Pedersen*
}

Department of Chemistry, University of Aarhus, DK-8000 Aarhus C, Denmark

\section{Dedicated to Professor Henning Lund on the occasion of his 70th birthday.}

Daasbjerg, K., Knudsen, S. R., Sonnichsen, K. N., Andrade, A. R. and Pedersen, S. U., 1999. Systematic Ranking of Nucleophiles as Electron Donors. - Acta Chem. Scand. 53: 938 948. (C) Acta Chemica Scandinavica 1999.

\begin{abstract}
A systematic ranking of different nucleophiles (including enolates, phenolates, thiophenolates, hydroxide, cyanide) with respect to their ability to stabilise the transition state of substitution reactions has been carried out in acetonitrile and dimethyl sulfoxide. The method is based on a comparison of the rate constant, $k_{\text {SUB }}$, for the substitution reaction between a given nucleophile and benzyl chloride with the rate constant. $k_{\mathrm{ET}}$. for the corresponding electron transfer from an aromatic radical anion to benzyl chloride. The ratio $k_{\mathrm{SUB}} / k_{\mathrm{ET}}$ expresses the rate enhancement due to electronic interaction in the transition state, $\Delta G_{\mathrm{Sta}}$, of the substitution reaction. In this study, $k_{\mathrm{SUB}} / k_{\mathrm{ET}}$ ratios between 5 and $10^{31}$ were determined corresponding to $\Delta G_{\mathrm{Sta}}$-values of $4-175 \mathrm{~kJ} \mathrm{~mol}^{-1}$. These values cover substitution reactions going from outer-sphere electron transfer to $S_{\mathrm{N}} 2$ with partial bond formation in the transition state. The $k_{\mathrm{SUB}} / k_{\mathrm{ET}}$ values are found to be largest for nucleophiles such as $\mathrm{OH}^{-}$and $\mathrm{CN}^{-}$with very poor electrondonating abilities (high oxidation potentials). When different types of nucleophile with similar oxidation potentials are compared, a decrease in $k_{\mathrm{SUB}} / k_{\mathrm{ET}}$ is observed going from sulfur- to carbon- and further to oxygen-centred nucleophiles. The ranking of nucleophiles in reactions involving electrophiles other than benzyl chloride is discussed with emphasis on steric hindrance and electronic effects.
\end{abstract}

Over the past 30 years electron transfer (ET) reactions have been suggested as important steps in many mechanisms. Different strategies have been developed to address this issue with most of them focusing on radical intermediates formed when a single electron is transferred between 'even-electron' donors and acceptors. ${ }^{1-4}$ The detection of radicals, however, does not imply that they are necessarily formed in the major reaction path if side reactions are possible. The reverse situation could also be envisioned in which a pair of radicals is formed by the ET reaction but the radicals are not detected because of a fast coupling reaction taking place within the solvent cage.

With the purpose of having a better description of the ET character in the transition state (TS) of substitution reactions, a kinetic method was developed in the $1980 \mathrm{~s} .{ }^{5-8}$ In particular, the work by Henning Lund extended the scope of this approach. ${ }^{9}$

$\mathrm{Nu}^{-}+\mathrm{RX} \stackrel{k_{\text {SUB }}}{\longrightarrow} \mathrm{Nu}-\mathrm{R}+\mathrm{X}^{-}$

$\mathrm{A}^{\cdot-}+\mathrm{RX} \stackrel{{ }^{k_{\mathrm{ET}}}}{\longrightarrow} \mathrm{A}+\mathrm{R}^{\cdot}+\mathrm{X}^{-}$

*To whom correspondence should be addressed.
The method is based on a comparison of the rate constant for the substitution reaction [eqn. (1)] between a nucleophile $\mathrm{Nu}^{-}$and a substrate/electrophile $\mathrm{RX}, k_{\text {SUB }}$, with the corresponding ET rate constant, $k_{\mathrm{ET}}$, obtained using an outer-sphere electron donor $\mathrm{A}^{--}$[eqn. (2)]. It is important that the standard potentials as well as the self-exchange reorganisation energies of the $\mathrm{A} / \mathrm{A}^{\cdot}$ - and $\mathrm{Nu} / \mathrm{Nu}^{-}$couples are equal. The compounds normally used as electron donors are aromatic radical anions and metal complexes. If a $k_{\mathrm{SUB}} / k_{\mathrm{ET}}$ ratio of about 1 is measured for a given substitution process, the nucleophile reacts with the electrophile with a rate as expected for an outer-sphere ET reaction. Accordingly, the nucleophile can be classified as an outer-sphere electron donor in this specific reaction. On the other hand, if a significantly larger $k_{\mathrm{SUB}} / k_{\mathrm{ET}}$ value is obtained, the activation energy must be smaller for the substitution reaction than for the corresponding outer-sphere ET reaction. Thus, the substitution reaction proceeds by inner-sphere ET with strong electronic interaction between the two reactants in the TS. Within this framework a polar mechanism such as $\mathrm{S}_{\mathrm{N}} 2$, in which a partial bond is formed between the nucleophilic and electrophilic centres in the TS, may be described as an inner-sphere ET. ${ }^{9-14}$ 
In general, the activation energy for the substitution reaction (1), $\Delta G_{\mathrm{SUB}}^{\ddagger}$, may be expressed as the difference between an outer-sphere ET activation energy, $\Delta G_{\mathrm{ET}}^{ \pm}$, and a stabilisation or interaction energy, $\Delta G_{\mathrm{Sta}}$, as stated in eqn. (3).

$$
\begin{aligned}
& \Delta G_{\mathrm{SUB}}^{\ddagger}=\Delta G_{\mathrm{ET}}^{\ddagger}-\Delta G_{\mathrm{Sta}} \\
& \Delta G_{\mathrm{ET}}^{\ddagger}=\Delta G_{\mathrm{o}}^{\ddagger}\left(1+\frac{\Delta G^{\circ}}{4 \Delta G_{\mathrm{o}}^{\ddagger}}\right)^{2} \\
& k_{\mathrm{ET}}=Z \exp \left[\frac{-\Delta G_{\mathrm{o}}^{\ddagger}}{R T}\left(1-\frac{F\left(E_{\mathrm{PhCH}_{2} \mathrm{Cl}}^{\circ}-E_{\mathrm{A} / \mathrm{A}}^{\circ}-\right)}{4 \Delta G_{\mathrm{o}}^{\ddagger}}\right)^{2}\right] \\
& \Delta G_{\mathrm{Sta}}=R T \ln \left(k_{\mathrm{SUB}} / k_{\mathrm{ET}}\right)
\end{aligned}
$$

In the Marcus treatment of outer-sphere ET the stabilisation energy is assumed to be negligible but in practice an upper limit of $4 \mathrm{~kJ} \mathrm{~mol}^{-1}$ is often used. ${ }^{15}$ The Marcus relation between $\Delta G_{\mathrm{ET}}^{ \pm}$and the free energy of the reaction, $\Delta G^{\circ}$, is given in eqn. (4), where $\Delta G_{\mathrm{o}}^{\ddagger}$ is the intrinsic barrier. ${ }^{15,16}$ According to Savéant this relationship is also adequate in the description of dissociative ET reactions. ${ }^{17}$ Expression (5) is derived by combining the Marcus and Eyring equations, in which $Z$ is the collision frequency $\left(=3 \times 10^{11} \mathrm{M}^{-1} \mathrm{~s}^{-1}\right), \quad E_{\mathrm{A} / \mathrm{A}^{*}}^{\circ}$ the standard potential of the aromatic compound and $E_{\mathrm{PhCH}_{2} \mathrm{Cl}}^{\circ}$ the standard potential of benzyl chloride.* For a substitution process $\Delta G_{\text {Sta }}$ may be of a substantial magnitude owing to partial bond formation in the TS and Marcus theory cannot be applied per se. In fact, if the structure of the TS is assumed to be symmetric the stabilisation energy corresponds to one half of the bond energy of the new bond formed during the process. Since the present study is concerned with the formation of carbon-carbon, carbon-oxygen or carbon-sulfur bonds with bond strengths of up to ca. $350 \mathrm{~kJ} \mathrm{~mol}^{-1}, \Delta G_{\mathrm{Sta}}$ is expected to vary in the range $4-175 \mathrm{~kJ} \mathrm{~mol}^{-1}$ for innersphere ET processes.

Experimentally, $\Delta G_{\mathrm{Sta}}$ is quantified from the measured $k_{\mathrm{SUB}} / k_{\mathrm{ET}}$ ratios as stated in eqn. (6). This expression is easily obtained on the basis of TS theory and it shows that an inner-sphere ET reaction with $\Delta G_{\text {Sta }}$ in the range $4-175 \mathrm{~kJ} \mathrm{~mol}^{-1}$ should be $5-10^{31}$ times faster than the corresponding outer-sphere ET. Still, outer-sphere ET may take place under appropriate conditions, for example, if a close approach between the two reactants and thus bond formation in the TS is prohibited by steric interference. ${ }^{2}$

In previous investigations of the ET character of substitution reactions, focus has been on reactions with $k_{\mathrm{SUB}} / k_{\mathrm{ET}}$ ratios in the range $1-10^{9} .^{7,9,19,20}$ The major point was to relate the variation in $k_{\mathrm{SUB}} / k_{\mathrm{ET}}$ to the steric conditions at the electrophilic centre with almost no attention paid to the nucleophilic part. In this paper, the

\footnotetext{
* The reduction of benzyl chloride presumably follows the dissociative pathway ${ }^{18}$ and the standard potential $E_{\mathrm{PhCH}_{2} \mathrm{Cl}}^{\circ}$ is then defined according to the electrode process: $\mathrm{PhCH}_{2} \mathrm{Cl}+\mathrm{e}$ $\rightleftarrows \mathrm{PhCH}_{2}{ }^{+}+\mathrm{Cl}^{-}$.
}

purpose is to describe in detail the role of the nucleophile and its features. In particular, we present a systematic ranking of nucleophiles in terms of their ability to stabilise the TS of substitution reactions. Benzyl chloride was chosen as the electrophile because of its high reactivity towards most anionic nucleophiles. Steric hindrance at the central primary carbon atom is small and most nucleophiles are free to approach the electrophilic centre to bonding distance without major geometric restrictions. Competing $\mathrm{S}_{\mathrm{N}} 1$ or elimination reactions may also be disregarded. These features have so far allowed the measurement of $k_{\text {SUB }}$ for a large number of nucleophiles as presented in Ref. 21 and more results are added in the present study. From the data, $k_{\mathrm{SUB}} / k_{\mathrm{ET}}$ values are obtained covering the whole accessible range of ratios from 1 to $10^{31}$.

\section{Results and discussion}

ET rate constants, $k_{\mathrm{ET}}$, for the reaction between different aromatic radical anions and benzyl chloride were measured in acetonitrile and dimethyl sulfoxide (DMSO). The $k_{\mathrm{ET}}$ values are collected in Tables 1 and 2 and in Figs. 1 and 2 they are depicted as plots of $\log k_{\mathrm{ET}}$ against the standard potential of the electron donors, $E_{\mathrm{A} / \mathrm{A}^{\circ-}}^{\circ}$ Although such plots should be parabolic according to

Table 1. Rate constants $k_{\mathrm{ET}}$ obtained for the reaction between different aromatic radical anions and benzyl chloride in acetonitrile-0.1 $\mathrm{M} \mathrm{Bu}_{4} \mathrm{NBF}_{4}$ at $20^{\circ} \mathrm{C}$.

\begin{tabular}{llll}
\hline Mediator & $-E_{\mathrm{AA}}^{\circ}-\mathrm{V}^{a}$ & $k_{\mathrm{ET}} / \mathrm{M}^{-1} \mathrm{~s}^{-1}$ & $\log k_{\mathrm{ET}}$ \\
\hline Anthracene & $1.974^{b}$ & $9.5 \times 10^{4 b}$ & 4.98 \\
9-Phenylanthracene & 1.912 & $3.2 \times 10^{4}$ & 4.51 \\
9,10-Diphenylanthracene & 1.886 & $1.8 \times 10^{4}$ & 4.26 \\
Benzophenone & 1.754 & $1.5 \times 10^{3}$ & 3.18 \\
Perylene & 1.667 & 410 & 2.61 \\
1,4-Dicyanobenzene & $1.620^{b}$ & 130 & 2.11 \\
Azobenzene & 1.332 & 2.8 & 0.45 \\
Phenazine & 1.168 & 0.11 & -0.96 \\
3-Nitrobenzophenone & 0.998 & $2.3 \times 10^{-2}$ & -1.64 \\
Anthraquinone & 0.882 & $1.0 \times 10^{-3}$ & -3.00 \\
\hline
\end{tabular}

${ }^{a}$ Vs. SCE. ${ }^{b}$ From Ref. 21.

Table 2. Rate constants $k_{\mathrm{ET}}$ obtained for the reaction between different aromatic radical anions and benzyl chloride in DMSO-0.1 M Bu $\mathrm{NBF}_{4}$ at $20^{\circ} \mathrm{C}$.

\begin{tabular}{lcll}
\hline Mediator & $-E_{\mathrm{A} / \mathrm{A}^{-}-}^{\circ} \mathrm{N}^{\mathrm{a}}$ & $k_{\mathrm{ET}} / \mathrm{M}^{-1} \mathrm{~s}^{-1}$ & $\log k_{\mathrm{ET}}$ \\
\hline Anthracene & 1.852 & $8.1 \times 10^{4}$ & 4.91 \\
9,10-Dimethylanthracene & 1.793 & $5.1 \times 10^{4}$ & 4.71 \\
9,10-Diphenylanthracene & 1.760 & $2.2 \times 10^{4}$ & 4.34 \\
Fluoranthene & 1.632 & 2700 & 3.43 \\
Perylene & 1.572 & 940 & 2.97 \\
Acenaphthylene & 1.533 & 400 & 2.60 \\
1,4-Dicyanobenzene & 1.485 & 180 & 2.26 \\
1,4-Diacetylbenzene & 1.407 & 21 & 1.32 \\
Phenazine & 1.082 & $6.3 \times 10^{-2}$ & -1.20 \\
Anthraquinone & 0.879 & $2.5 \times 10^{-3}$ & -2.60 \\
\hline
\end{tabular}

${ }^{a}$ Vs. SCE 


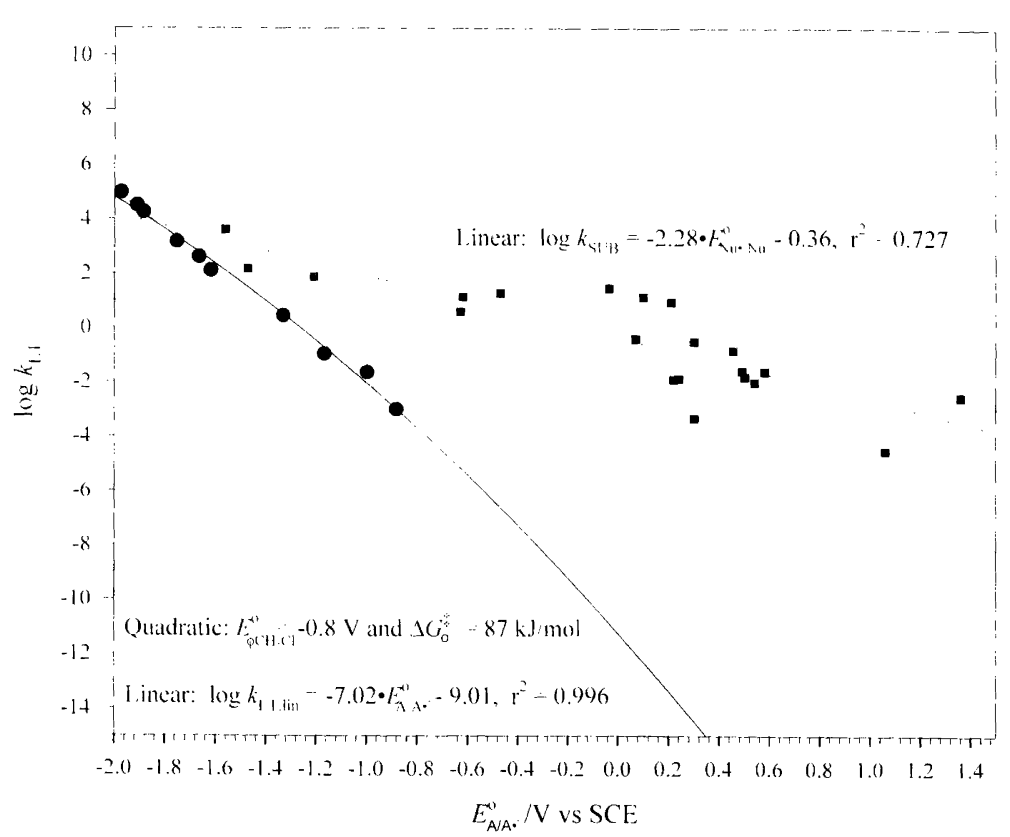

Fig. 1. Logarithm of the rate constant $k_{E T}$ of the ET reaction between different aromatic radical anions and benzyl chloride versus the standard potential of the aromatic compounds $E_{\mathrm{A} / \mathrm{A}}$. in acetonitrile-0.1 $\mathrm{M} \mathrm{TBABF}_{4}(\mathbf{)})$. Linear (dashed line) and quadratic (solid curve) correlations are included. Data points $\left(E_{\mathrm{Nu}^{\prime} / \mathrm{Nu}}, \log k_{\mathrm{SUB}}\right)$ pertaining to the substitution reaction between different anionic nucleophiles and benzyl chloride are inserted $(\mathbf{E})$ and the linear correlation obtained is shown as the straight dotted line.

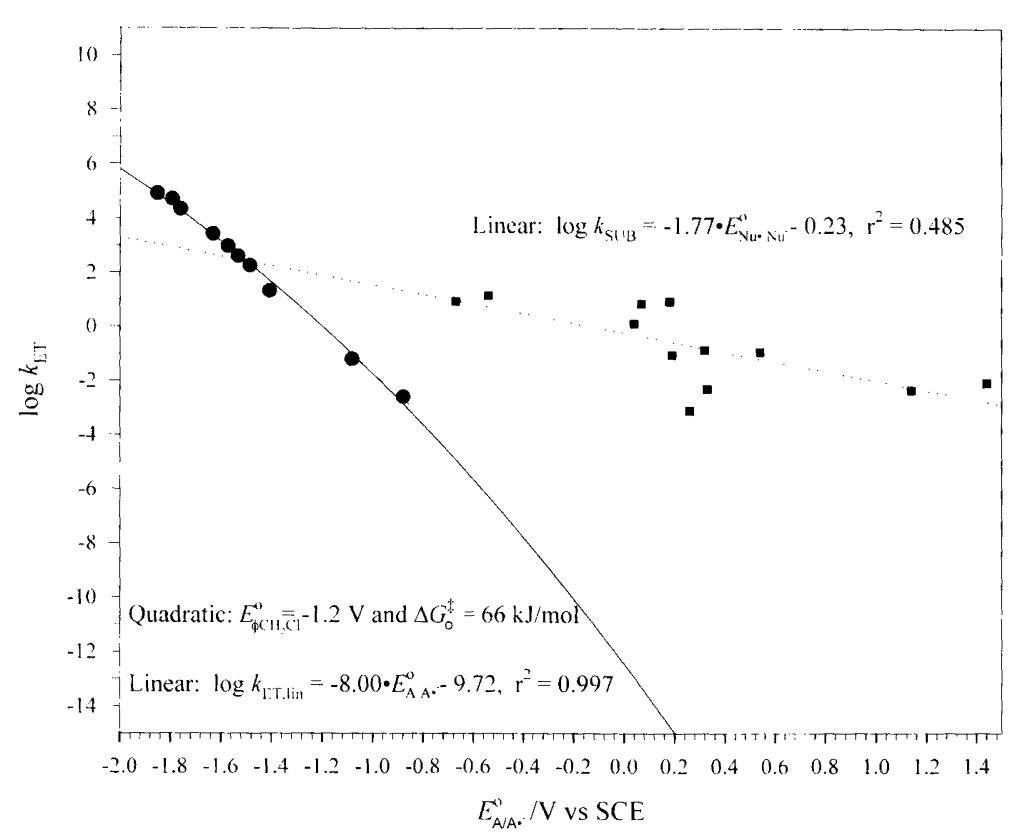

Fig. 2. Logarithm of the rate constant $k_{E T}$ of the ET reaction between different aromatic radical anions and benzyl chloride

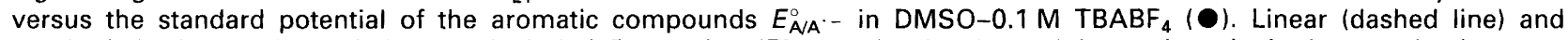

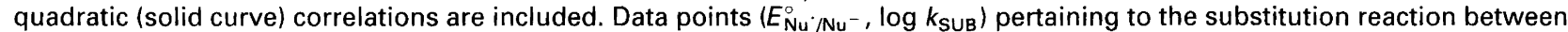
different anionic nucleophiles and benzyl chloride are inserted $(\mathbf{E})$ and the linear correlation obtained is shown as the straight dotted line.

eqn. (5), simple linear regression of the data points results in good fits indeed as shown by the dashed lines in the figures. The slopes found for acetonitrile and DMSO are $-7.0 \mathrm{~V}^{-1}$ and $-8.0 \mathrm{~V}^{-1}$, respectively, which by being multiplied by $-R T \ln 10 / F$ are converted into slopes of $\Delta G_{\mathrm{ET}}^{ \pm} / \Delta G^{\circ}=0.41$ and 0.47 .

The quadratic relationship (5) may also be fitted to the data points as illustrated by the solid curves in the 
figures. Since the curvature is hardly discernible this enables only a rather crude estimation of $E_{\mathrm{PhCH}_{2} \mathrm{Cl}}^{\circ}$ and $\Delta G_{\mathrm{o}}^{\ddagger}$. For acetonitrile: $E_{\mathrm{PhCH}_{2} \mathrm{Cl}}^{\circ}=-0.8 \pm 0.1 \mathrm{~V}$ vs. $\mathrm{SCE}$, $\Delta G_{\mathrm{o}}^{\ddagger}=87 \pm 5 \mathrm{~kJ} \mathrm{~mol}^{-1}$ and for DMSO: $E_{\mathrm{PhCH}_{2} \mathrm{Cl}}^{\circ}=$ $-1.2 \pm 0.1 \mathrm{~V}$ vs. SCE, $\Delta G_{\mathrm{o}}^{\ddagger}=66 \pm 3 \mathrm{~kJ} \mathrm{~mol}^{-1}$. Actually, the above $E_{\mathrm{PhCH}_{2} \mathrm{Cl}}^{\circ}$ values are close to thermodynamically calculated values. ${ }^{18}$ The finding of large intrinsic barriers $\Delta G_{\mathrm{o}}^{\ddagger}$ is also in accordance with expectation since the reduction process of benzyl chloride is accompanied by bond fragmentation of the relatively strong carbonchlorine bond. Thus, on the present basis the parabolic relationship cannot be rejected and we decided to use both correlations in the further treatment of the kinetic data. Interestingly, for other electron acceptors such as bromides and in particular sulfides, the reduction of which is associated with a smaller intrinsic barrier, the situation is less ambiguous and here both distinct linear ${ }^{22}$ and parabolic relationships are observed. ${ }^{23}$

The rate constant expected for a given substitution reaction, if it were to proceed by an ET process, may be obtained from either the linear or parabolic correlation by inserting the value of the standard potential of the nucleophile involved, $E_{\mathrm{Nu} / \mathrm{Nu}^{-}}^{\circ} \cdot E_{\mathrm{Nu}^{\cdot} / \mathrm{Nu}^{-}}^{\circ}$ is obtained in linear sweep voltammetry from the oxidative peak potential of $\mathrm{Nu}^{-}$(see the Experimental for details). ${ }^{21,24-26}$ The thus calculated $k_{\mathrm{ET}, \text { lin }}$ and $k_{\mathrm{ET} \text {,par }}$ values are listed along with $E_{\mathrm{Nu}}^{\circ} / \mathrm{Nu}^{-}$in Tables 3 and 4 .

The maximum difference between $k_{\mathrm{ET} \text {,lin }}$ and $k_{\mathrm{ET} \text {,par }}$ constitutes 'only' $40 \%$ as long as $E_{\mathrm{Nu}}^{\circ} / \mathrm{Nu}^{-}$- is positioned within the potential interval of the aromatic mediators from $-2.0 \mathrm{~V}$ to $-0.8 \mathrm{~V}$ vs. SCE. Obviously, the difference becomes larger, if the correlations are applied outside this potential interval. For instance, when the rate constants are calculated at a potential of $E_{\mathrm{Nu}^{\circ} / \mathrm{Nu}^{-}}^{\circ}=$ $+1.2 \mathrm{~V}$, i.e. an extrapolation of $2 \mathrm{~V}$ from the nearest data point, the ratio is a factor of $10^{8}$. However, even such a factor is acceptable for our purpose considering that $k_{\mathrm{SUB}} / k_{\mathrm{ET}}$ ratios as high as $10^{31}$ may be anticipated for inner-sphere ET reactions in this region. Furthermore, it has no effect on the ranking of the different nucleophiles studied in this paper.

The rate constants, $k_{\mathrm{SUB}}$, obtained for the substitution reactions of the nucleophiles with benzyl chloride are summarised in Tables 3 and 4 and in Figs. 1 and 2. The general feature of the $k_{\text {SUB }}$ values is as described in Ref. 21 , i.e. the more easily oxidisable anions with low values of $E_{\mathrm{Nu}^{\prime} / \mathrm{Nu}^{-}}^{\circ}$ react faster with benzyl chloride. In fact, a rough linear correlation between $\log k_{\text {SUB }}$ and $E_{\mathrm{Nu} / \mathrm{Nu}^{-}}^{\circ}$ exists with slopes of $-2.3 \mathrm{~V}^{-1}$ and $-1.8 \mathrm{~V}^{-1}$ for acetonitrile and DMSO, respectively, as indicated by the dotted straight lines in the figures. The scattering of the data points is quite significant and good to excellent correlations are obtained only if families of nucleophiles, in terms of carbon anions, oxygen anions or sulfur anions, are selected. This is not surprising since $E_{\mathrm{Nu} / \mathrm{Nu}^{-}}^{\circ}$ expresses the readiness of the nucleophile to give up a single electron and it takes no specific electronic or structural properties of the two reactants into account, which would be of major importance for inner-sphere ET reactions.

In the last two columns of Tables 3 and 4 the values of $k_{\mathrm{SUB}} / k_{\mathrm{ET}}$ and $\Delta G_{\mathrm{Sta}}$ calculated from eqn. (6) are included.* The most profound feature of these is the increase observed as the electron-donating ability of the nucleophile is diminished, i.e. when $E_{\mathrm{Nu}}^{\circ}{ }^{\circ} \mathrm{Nu}^{-}$becomes higher. This is due to the fact that the sensitivity of the rate constant $k_{\mathrm{SUB}}$ towards $E_{\mathrm{Nu} / \mathrm{Nu}^{-}}^{\circ}$ is much smaller compared with the influence of $E_{\mathrm{A} / \mathrm{A}}^{\circ}$ - on $k_{\mathrm{ET}}$. In fact, the slope difference of the two free energy plots of $5.5 \pm 0.8 \mathrm{~V}^{-1}$ corresponds to the slope of a $\log k_{\mathrm{SUB}} / k_{\mathrm{ET}}$ vs. $E^{\circ}$ plot. A straightforward interpretation of this behaviour is that while strongly electron-donating nucleophiles are able to transfer an electron to the electrophile from a long distance without efficient orbital overlap the nucleophiles with poorer electron-donating abilities need the stabilising effect of bond formation in the TS, i.e. a close approach to the electrophile, in order to react at all.

The solvent effect on $k_{\mathrm{SUB}} / k_{\mathrm{ET}}$ is relatively small with a tendency to increase on going from acetonitrile to DMSO as illustrated by the results obtained for fluorenide, 4-methoxythiophenolate, thiophenolate, 4-nitrothiophenolate, phenolate, hydroxide and cyanide. Ion-pairing effects are also believed to be of minor importance, since tetrabutylammonium from the supporting electrolyte is the counter ion of the anionic nucleophiles in most cases. ${ }^{30}$ For fluorenide the effect of using $\mathrm{K}^{+}$as counter ion was studied (entries 4 and 5, Table 3 ). Interestingly, $E_{\mathrm{Nu} / \mathrm{Nu}^{-}}^{\circ}$ is found to be unaffected while $k_{\mathrm{SUB}}$ and the $k_{\mathrm{SUB}} / k_{\mathrm{ET}}$ ratio are increased. This points to a much stronger interaction of $\mathrm{K}^{+}$with the developing chloride in the TS than with the delocalised fluorenide in the initial state.

In Fig. 3, a selection of nucleophiles is ranked according to the $k_{\mathrm{SUB}} / k_{\mathrm{ET}}$ and $\Delta G_{\mathrm{Sta}}$ values obtained in acetonitrile and DMSO on the basis of the quadratic approach. The nucleophiles cover almost the whole accessible range of $k_{\mathrm{SUB}} / k_{\mathrm{ET}}$ ratios from 1 to $10^{31}$, going from outersphere ET to $\mathrm{S}_{\mathrm{N}} 2$ reactions with partial bond formation in the TS. The largest $k_{\mathrm{SUB}} / k_{\mathrm{ET}}=1.9 \times 10^{31}$ is found for the reaction in DMSO between $\mathrm{CN}^{-}$and benzyl chloride yielding benzyl cyanide in an exothermic process. According to eqn. (6) this corresponds to a $\Delta G_{\text {Sta }}$ of $175 \mathrm{~kJ} \mathrm{~mol}^{-1}$, which is $50 \mathrm{~kJ} \mathrm{~mol}^{-1}$ below half of the bond dissociation energy of the $\mathrm{C}-\mathrm{CN}$ bond in benzyl cyanide $\left(\approx 450 \mathrm{~kJ} \mathrm{~mol}^{-1}\right)$. As discussed in the introduction, such high values of $k_{\mathrm{SUB}} / k_{\mathrm{ET}}$ and $\Delta G_{\mathrm{Sta}}$ are close to

\footnotetext{
* For a few nucleophiles such as hydroxide and cyanide the $k_{\mathrm{SUB}} / k_{\mathrm{ET}}$ ratio should be considered as a minimum value since the self-exchange reorganisation energy of the $\mathrm{OH}^{*} / \mathrm{OH}^{-}$and $\mathrm{CN}^{*} / \mathrm{CN}^{-}$couples is somewhat higher than of $\mathrm{A} / \mathrm{A}^{-\cdots} .4,20$ Previous studies have also shown that the ET reaction between $\mathrm{A}^{-}$and sterically non-hindered electrophiles may possess some inner-sphere character and not be truly outersphere. $^{11,22,27-29}$ This effect would lower systematically the $k_{\mathrm{SUB}} / k_{\mathrm{ET}}$ ratios obtained but not influence the ranking of nucleophiles.
} 
Table 3. Rate constants $k_{\mathrm{SUB}}$ for the substitution reaction between various anionic nucleophiles (with the standard potential

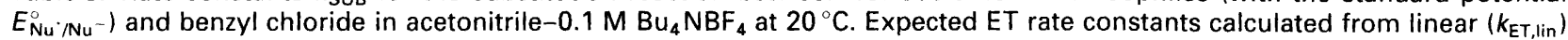
and parabolic $\left(k_{\mathrm{ET}, \text { par }}\right)$ fits are included as well as the $k_{\mathrm{SUB}} / k_{\mathrm{ET}}$ ratio and $\Delta G_{\mathrm{Sta}}$.

\begin{tabular}{|c|c|c|c|c|c|}
\hline $\begin{array}{l}\text { Structure and name } \\
\text { of } \mathrm{Nu}^{-}{ }^{-a}\end{array}$ & $k_{\mathrm{SUB}} / \mathrm{M}^{-1} \mathrm{~s}^{-1}$ & $E_{\mathrm{Nu} / \mathrm{Nu}^{-}}^{\circ} / \mathrm{V}^{b}$ & $\begin{array}{l}k_{\mathrm{ET}, \mathrm{lin}} / \mathrm{M}^{-1} \mathrm{~s}^{-1} \\
k_{\mathrm{ET}, \mathrm{par}} / \mathrm{M}^{-1} \mathrm{~s}^{-1}\end{array}$ & $\begin{array}{l}k_{\mathrm{SUB}} / k_{\mathrm{ET}, \mathrm{lin}} \\
k_{\mathrm{SUB}} / k_{\mathrm{ET}, \mathrm{par}}\end{array}$ & $\Delta G_{\mathrm{Sta}} / \mathrm{kJ} \mathrm{mol}^{-1}$ \\
\hline$N \quad-$ & $4.1 \times 10^{3 c}$ & $-1.563^{c}$ & $\begin{array}{l}90 \\
1.3 \times 10^{2}\end{array}$ & $\begin{array}{l}45 \\
32\end{array}$ & $\begin{array}{l}9.3 \\
8.4\end{array}$ \\
\hline
\end{tabular}

1,4-Dihydro-4-methoxycarbonyl-

1-methylpyridine anion

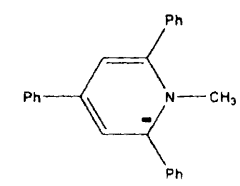

1-Methyl-2,4,6-triphenylpyridine anion<smiles></smiles>

2,4,6-Triphenylthiopyran anion<smiles>[Z6]c1ccccc1-c1ccccc1C</smiles>

$14^{d}$

$1.5 \times 10^{2 c}$

$-1.473^{c}$

21
32

7.1

4.8

4.8

3.8

$76^{c}$

$-1.210^{c}$

0.30

0.40

$2.5 \times 10^{2}$

$1.9 \times 10^{2}$

13

13

Fluorenide<smiles>c1ccc2c(c1)[CH+]c1ccccc1-2</smiles>

$4.0^{\circ}$

$-0.63^{c}$

$2.6 \times 10^{-5}$

$1.6 \times 10^{5}$

$7.0 \times 10^{-6}$

$5.7 \times 10^{5}$

29

32

Fluorenide<smiles>N#CCc1ccccc1</smiles>

$19^{f}$

$-0.46^{f}$

$1.6 \times 10^{-6}$

$2.0 \times 10^{-7}$

$1.2 \times 10^{7}$

$9.6 \times 10^{7}$

40

Cyanophenylmethanide<smiles>COc1ccc([S-])cc1</smiles>

4-Methoxythiophenolate<smiles>CCOC(=O)C(C)C(=O)OCC</smiles>

Diethyl methylmalonate anion<smiles>[S-]c1ccccc1</smiles>

Thiophenolate $29^{d}$

$$
-0.035^{g}
$$

$1.9 \times 10^{-9}$

$1.5 \times 10^{-11}$

$1.6 \times 10^{10}$

$1.9 \times 10^{12}$

57

69

$0.40^{f}$

$0.08^{f}$

$2.7 \times 10^{-10}$

$1.5 \times 10^{9}$

$8.4 \times 10^{-13}$

$4.8 \times 10^{11}$

51

66

$14^{d}$

$0.10^{g}$

$1.9 \times 10^{-10}$

$5.2 \times 10^{-13}$

$7.2 \times 10^{10}$

$2.7 \times 10^{13}$

61

75 


\begin{tabular}{|c|c|c|c|c|c|}
\hline $\begin{array}{l}\text { Structure and name } \\
\text { of } \mathrm{Nu}:^{-a}\end{array}$ & $k_{\mathrm{SUB}} / \mathrm{M}^{-1} \mathrm{~s}^{-1}$ & $E_{\mathrm{Nu} / \mathrm{Nu}}^{\circ}-/ \mathrm{V}^{b}$ & $\begin{array}{l}k_{\mathrm{ET}, \mathrm{lin}} / \mathrm{M}^{-1} \mathrm{~s}^{-1} \\
k_{\mathrm{ET}, \mathrm{par}} / \mathrm{M}^{-1} \mathrm{~s}^{-1}\end{array}$ & $\begin{array}{l}k_{\mathrm{SUB}} / k_{\mathrm{ET}, \mathrm{lin}} \\
k_{\mathrm{SUB}} / k_{\mathrm{ET}, \mathrm{par}}\end{array}$ & $\Delta G_{\mathrm{Sta}} / \mathrm{kJ} \mathrm{mol}^{-1}$ \\
\hline & $9.3^{f}$ & $0.20^{f}$ & $\begin{array}{l}3.9 \times 10^{-11} \\
4.3 \times 10^{-14}\end{array}$ & $\begin{array}{l}2.4 \times 10^{11} \\
2.2 \times 10^{14}\end{array}$ & $\begin{array}{l}64 \\
80\end{array}$ \\
\hline
\end{tabular}

2-Naphthalenethiolate

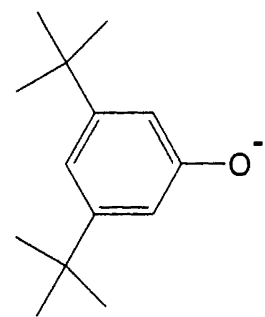

$\begin{array}{lllll}1.3 \times 10^{-2 f} & 0.23^{f} & 2.4 \times 10^{-11} & 5.5 \times 10^{8} & 49 \\ & & 2.0 \times 10^{-14} & 6.4 \times 10^{11} & 66\end{array}$

3,5-Di-tert-butylphenolate

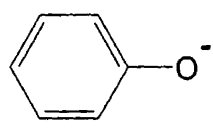

$1.4 \times 10^{-2 f}$

$0.24^{h}$

$2.0 \times 10^{-11}$

$7.0 \times 10^{8}$

$1.6 \times 10^{-14} \quad 8.8 \times 10^{11}$

50

Phenolate<smiles>[O-]c1ccc(Cl)cc1</smiles>

$$
4.8 \times 10^{-4 f}
$$

$0.30^{i}$

$7.6 \times 10^{-12}$

$6.3 \times 10^{7}$

$3.5 \times 10^{-15} \quad 1.4 \times 10^{11}$

44

4-Chlorophenolate<smiles>c1cc[n-]c1</smiles>

$0.32^{f}$

$0.31^{f}$

$6.5 \times 10^{-12}$

$4.9 \times 10^{10}$

$2.7 \times 10^{-15} \quad 1.2 \times 10^{14}$

60

Pyrrolate anion<smiles>O=[N+]([O-])c1ccc([S-])cc1</smiles>

$0.15^{d}$

$0.455^{g}$

$6.3 \times 10^{-13}$

$6.1 \times 10^{-17}$

$2.4 \times 10^{11}$

$2.5 \times 10^{15}$

64

4-Nitrothiophenolate<smiles>CCC(=O)OC</smiles>

$2.6 \times 10^{-2 f}$

$0.50^{f}$

$3.0 \times 10^{-13}$

$1.9 \times 10^{-17}$

$8.6 \times 10^{10}$

$1.4 \times 10^{15}$

61

Cyano(methoxycarbonyl)methanide<smiles>CCOC(=O)CC(C)=O</smiles>

$1.6 \times 10^{-2 f}$

$0.51^{f}$

$2.6 \times 10^{-13}$

$1.4 \times 10^{-17}$

$6.2 \times 10^{10}$

$1.1 \times 10^{15}$

61
84

Ethyl acetoacetate anion<smiles>N#CCC#N</smiles>

$$
1.0 \times 10^{-2 f}
$$

$0.55^{f}$

$1.4 \times 10^{-13}$

$7.4 \times 10^{10}$ $2.1 \times 10^{15}$

61

Dicyanomethanide<smiles></smiles>

$2.5 \times 10^{-2 f}$

$0.59^{f}$

$7.1 \times 10^{-14}$
$1.6 \times 10^{-18}$

$3.5 \times 10^{11}$ $1.5 \times 10^{16}$

65

91 
Table 3. (Continued.)

\begin{tabular}{|c|c|c|c|c|c|}
\hline $\begin{array}{l}\text { Structure and name } \\
\text { of } \mathrm{Nu}^{-a}\end{array}$ & $k_{\mathrm{SUB}} / \mathrm{M}^{-1} \mathrm{~s}^{-1}$ & $E_{\mathrm{Nu} / \mathrm{Nu}^{-}} / \mathrm{V}^{b}$ & $\begin{array}{l}k_{\mathrm{ET}, \mathrm{lin}} / \mathrm{M}^{-1} \mathrm{~s}^{-1} \\
k_{\mathrm{ET}, \mathrm{par}} / \mathrm{M}^{-1} \mathrm{~s}^{-1}\end{array}$ & $\begin{array}{l}k_{\mathrm{SUB}} / k_{\mathrm{ET}, \text { lin }} \\
k_{\mathrm{SUB}} / k_{\mathrm{ET}, \mathrm{par}}\end{array}$ & $\Delta G_{\mathrm{Sta}} / \mathrm{kJ} \mathrm{mol}^{-1}$ \\
\hline $\begin{array}{l}\mathrm{OH}^{-} \\
\text {Hydroxide }\end{array}$ & $3.0 \times 10^{-5 j}$ & $1.06^{k}$ & $\begin{array}{l}3.6 \times 10^{-17} \\
2.5 \times 10^{-24}\end{array}$ & $\begin{array}{l}8.5 \times 10^{11} \\
1.2 \times 10^{19}\end{array}$ & $\begin{array}{r}67 \\
107\end{array}$ \\
\hline $\begin{array}{l}\mathrm{CN}^{-} \\
\text {Cyanide }\end{array}$ & $2.9 \times 10^{-3 j}$ & $1.36^{k}$ & $\begin{array}{l}2.8 \times 10^{-19} \\
2.6 \times 10^{-28}\end{array}$ & $\begin{array}{l}1.0 \times 10^{16} \\
1.1 \times 10^{25}\end{array}$ & $\begin{array}{r}90 \\
140\end{array}$ \\
\hline
\end{tabular}

${ }^{a}$ Tetrabutylammonium salt if nothing else is indicated. ${ }^{b}$ Vs. SCE. ${ }^{c}$ Cyclic or linear sweep voltammetric measurements. ${ }^{d}$ Stopped-flow UV measurement. ${ }^{\circ}$ Dip-probe UV measurement. ${ }^{f}$ From Ref. 21 . The kinetic shift of $E_{\mathrm{ox}, \mathrm{p}}$ relative to $E_{\mathrm{Nu} / \mathrm{Nu}}{ }^{\circ}$ is estimated to be $-0.101 \mathrm{~V}$ on the basis of eqn. (7). ${ }^{g}$ From Ref. 25 . ${ }^{h}$ From Ref. 26. 'Interpolated from the Hammett relationship given in Ref. 26. ${ }^{j}$ Monitored by ${ }^{1} \mathrm{H}$ NMR. ${ }^{k}$ From Ref. 4, pp. 47 and 62.

the upper limits of the two scales. The reactions of $\mathrm{OH}^{-}$ and thiophenolates are also characterised by substantial $k_{\mathrm{SUB}} / k_{\mathrm{ET}}$ values in the order of $10^{15} 10^{25}$. The smallest ratio of 4.8 is found for the anion of 1-methyl-2,4,6triphenylpyridine, a highly delocalised and strongly electron-donating nucleophile.

It is also interesting to compare the $\Delta G_{\text {Sta }}$ values for C-, O- and S-centred nucleophiles with similar oxidation potentials. For instance, in the case of diethyl methylmalonate anion and thiophenolate (entries 8 and 9 , Table 3) $\Delta G_{\text {Sta }}$ is higher for the latter by about $10 \mathrm{~kJ} \mathrm{~mol}^{-1}$. Similarly, 2-naphthalenethiolate is a better inner-sphere ET donor with a higher $\Delta G_{\text {Sta }}$ of $15 \mathrm{~kJ} \mathrm{~mol}^{-1}$ compared with 3,5-di-tert-butylphenolate (entries 10 and 11, Table 3 ). Thus, the general ranking of nucleophiles in terms of their ability to stabilise the transition state is $\mathrm{RS}^{-}>\mathrm{R}_{3} \mathrm{C}^{-}>\mathrm{RO}^{-}$, i.e. the same as their order of reactivity. ${ }^{21}$ Traditionally, this is explained by the high polarisability of $\mathrm{RS}^{-}$which allows it to bring a greater degree of electron density to the substrate than the smaller nucleophiles whose electron clouds are held more tightly; that $\mathrm{R}_{3} \mathrm{C}^{-}>\mathrm{RO}^{-}$is attributed to the higher basicity of the former anion. An interesting aspect of our comparison is that it is carried out for nucleophiles
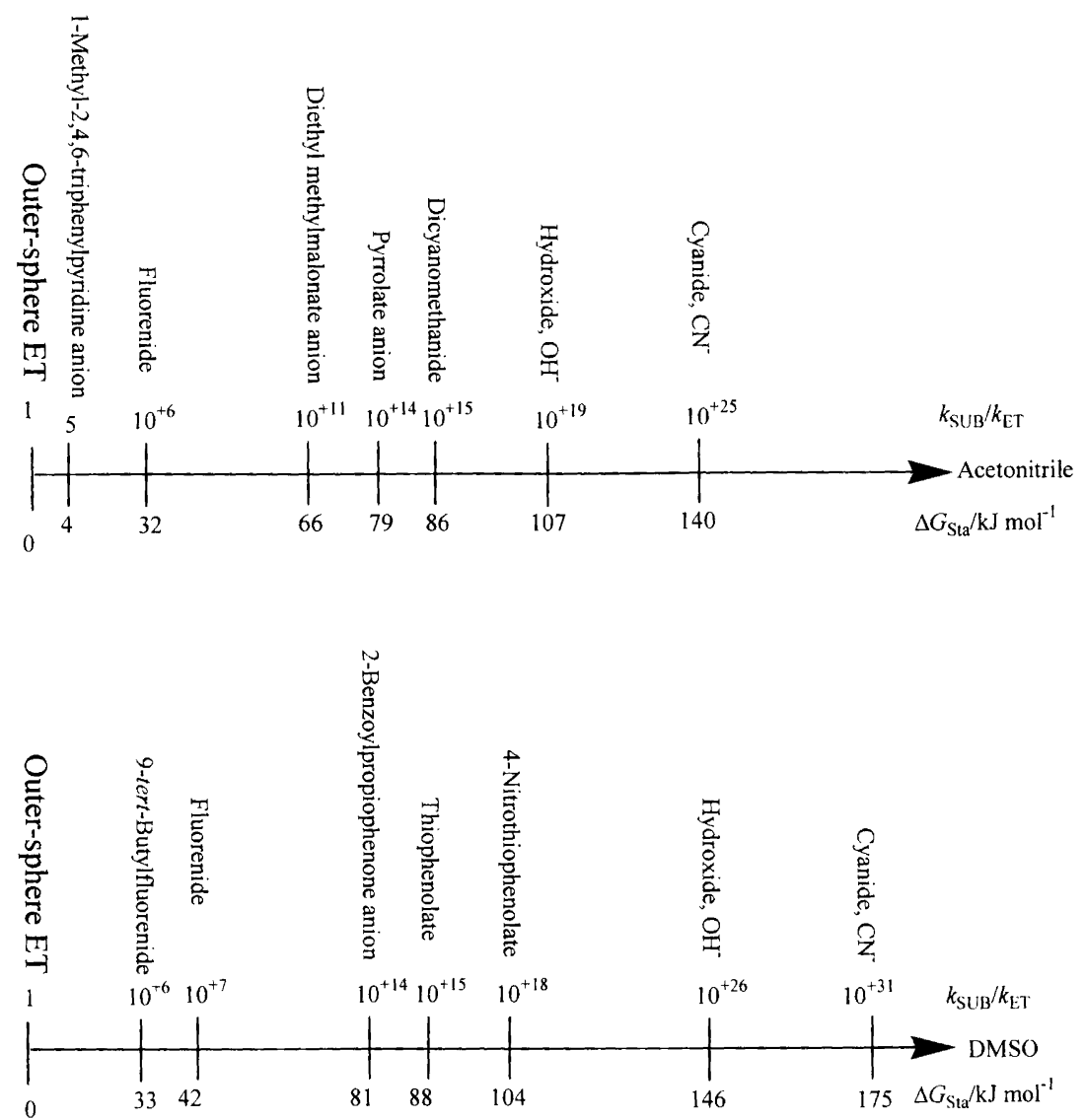

Fig. 3. Ranking of a selection of nucleophiles with respect to values of $k_{\mathrm{SUB}} / k_{\mathrm{ET}}$ and $\Delta G_{\mathrm{Sta}}$ obtained in the quadratic approach for the substitution reaction with benzyl chloride. 
Table 4. Rate constants for the substitution reaction between various anionic nucleophiles (with the standard potential $E_{\mathrm{Nu}^{\circ} / \mathrm{Nu}^{-}}{ }^{-}$) and benzyl chloride in DMSO-0.1 $\mathrm{M} \mathrm{Bu}_{4} \mathrm{NBF}_{4}$ at $20^{\circ} \mathrm{C}$. Expected ET rate constants calculated from linear $\left(k_{\mathrm{ET}, \text { in }}\right)$ and parabolic $\left(k_{\mathrm{ET}, \text { par }}\right)$ fits are included as well as the $k_{\mathrm{SUB}} / k_{\mathrm{ET}}$ ratio and $\Delta G_{\mathrm{Sta}}$.

\begin{tabular}{|c|c|c|c|c|c|}
\hline $\begin{array}{l}\text { Structure and name } \\
\text { of } \mathrm{Nu}^{-a}\end{array}$ & $k_{\text {SUB }} / \mathrm{M}^{-1} \mathrm{~s}^{-1}$ & $E_{\mathrm{Nu} / \mathrm{Nu}}^{\circ}-/ \mathrm{V}^{b}$ & $\begin{array}{l}k_{\mathrm{ET}, \mathrm{lin}} / \mathrm{M}^{-1} \mathrm{~s}^{-1} \\
k_{\mathrm{ET}, \mathrm{par}} / \mathrm{M}^{-1} \mathrm{~s}^{-1}\end{array}$ & $\begin{array}{l}k_{\mathrm{SUB}} / k_{\mathrm{ET}, \mathrm{lin}} \\
k_{\mathrm{SUB}} / k_{\mathrm{ET}, \text { par }}\end{array}$ & $\Delta G_{\mathrm{Sta}} / \mathrm{kJ} \mathrm{mol}^{-1}$ \\
\hline & $8.6^{d}$ & $-0.67^{e}$ & $\begin{array}{l}4.4 \times 10^{-5} \\
1.2 \times 10^{-5}\end{array}$ & $\begin{array}{l}2.0 \times 10^{5} \\
7.2 \times 10^{5}\end{array}$ & $\begin{array}{l}30 \\
33\end{array}$ \\
\hline
\end{tabular}

9-tert-Butylfluorenide ${ }^{c}$<smiles>c1ccc2c(c1)Cc1ccccc1-2</smiles>

$5.4 \times 10^{-7} \quad 2.6 \times 10^{7} \quad 42$

Fluorenide $^{f}$<smiles>COc1ccc([S-])cc1</smiles>

4-Methoxythiophenolate ${ }^{g}$<smiles>[O-]c1cccc2ccccc12</smiles>

1-Naphtholate<smiles>[Y]c1ccc2ccccc2c1</smiles>

$9.1 \times 10^{-2 d}$

$0.18^{\prime}$ $6.9 \times 10^{-12}$
$2.0 \times 10^{-15}$

$1.3 \times 10^{10}$ $4.5 \times 10^{13}$

57
77

2-Naphtholate ${ }^{k}$<smiles>[Y][S-]c1ccccc1</smiles>

$8.7^{d}$

$0.14^{d}$<smiles></smiles>

Phenolate $^{n}$<smiles></smiles>

$7.9 \times 10^{-4 p}$

$0.26^{q}$

$7.6 \times 10^{-11}$
$8.9 \times 10^{-14}$

$1.7 \times 10^{10}$

$1.5 \times 10^{13}$

57

74

$5.2 \times 10^{-11}$

$1.4 \times 10^{11}$

62

$5.0 \times 10^{-14}$

$1.4 \times 10^{14}$

79

Thiophenolate $^{m}$

$5.3 \times 10^{-13}$

$2.7 \times 10^{11}$

$4.6 \times 10^{15}$

64

$3.0 \times 10^{-17}$

$1.3 \times 10^{12}$

68

$2.0 \times 10^{-15}$

$4.3 \times 10^{15}$

88 


\begin{tabular}{|c|c|c|c|c|c|}
\hline $\begin{array}{l}\text { Structure and name } \\
\text { of } \mathrm{Nu}^{-a}\end{array}$ & $k_{\text {SUB }} / \mathrm{M}^{-1} \mathrm{~s}^{-1}$ & $E_{\mathrm{Nu} / \mathrm{Nu}^{-}} / \mathrm{V}^{b}$ & $\begin{array}{l}k_{\mathrm{ET}, \mathrm{in}} / \mathrm{M}^{-1} \mathrm{~s}^{-1} \\
k_{\mathrm{ET}, \mathrm{par}} / \mathrm{M}^{-1} \mathrm{~s}^{-1}\end{array}$ & $\begin{array}{l}k_{\mathrm{SUB}} / k_{\mathrm{ET}, \mathrm{lin}} \\
k_{\mathrm{SUB}} / k_{\mathrm{ET}, \text { par }}\end{array}$ & $\Delta G_{\mathrm{Sta}} / \mathrm{kJ} \mathrm{mol}^{-1}$ \\
\hline${ }_{\|} K^{+}$ & $5.1 \times 10^{-3 p}$ & $0.33^{r}$ & $\begin{array}{l}4.4 \times 10^{-13} \\
2.2 \times 10^{-17}\end{array}$ & $\begin{array}{l}1.2 \times 10^{10} \\
2.3 \times 10^{14}\end{array}$ & $\begin{array}{l}56 \\
81\end{array}$ \\
\hline
\end{tabular}

2-Benzoylpropiophenone anion

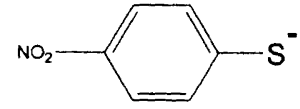

4-Nitrothiophenolate ${ }^{s}$

$\mathrm{OH}^{-}$

Hydroxide

$\mathrm{CN}^{-}$

Cyanide

$$
0.12^{d}
$$

$$
4.5 \times 10^{-3 t}
$$

$8.5 \times 10^{-3 t}$

$$
0.54^{h}
$$

$1.14^{u}$

$1.44^{u}$
$9.1 \times 10^{-15}$
$3.1 \times 10^{-20}$

$1.3 \times 10^{13}$
$3.9 \times 10^{18}$

74

104

${ }^{a}$ Tetrabutylammonium salt if nothing else is indicated. ${ }^{b} \mathrm{Vs}$. SCE. ${ }^{c}$ Orange, $\lambda_{\max }=478 \mathrm{~nm}$. ${ }^{d}$ Dip-probe UV measurement. ${ }^{e}$ From Ref. 24. ${ }^{f}$ Orange, $\lambda_{\max }=477 \mathrm{~nm}$. ${ }^{g}$ Pale green, $\lambda_{\max }=345 \mathrm{~nm}$. ${ }^{h}$ From Ref. 25 and shifted $0.08 \mathrm{~V}$ because of solvent change. 'Pale green, $\lambda_{\max }=348 \mathrm{~nm}$. ${ }^{i} E_{\mathrm{ox}, \mathrm{p}}=0.00 \mathrm{~V}$ vs. SCE at $\mathrm{v}=1 \mathrm{~V} \mathrm{~s}, C_{0}=3.2 \mathrm{mM}, k_{\mathrm{DIM}}$ assumed to be equal to $10^{9} \mathrm{M}^{-1} \mathrm{~s}^{-1}$. Kinetic shift in a DIM1 mechanism $=0.069 \mathrm{~V}$. ${ }^{k} \mathrm{Green}, \lambda_{\max }=390 \mathrm{~nm}$. ${ }^{\prime} E_{\mathrm{ox}, \mathrm{p}}=0.11 \mathrm{~V} \mathrm{vs}$. SCE at $\mathrm{V}=1 \mathrm{~V} \mathrm{~s}{ }^{-1}, C_{\mathrm{o}}=$ $3.9 \mathrm{mM}, k_{\text {DIM }}$ assumed to be equal to $10^{9} \mathrm{M}^{-1} \mathrm{~s}^{-1}$. Kinetic shift in a DIM1 mechanism $=0.071 \mathrm{~V}$. ${ }^{\mathrm{m}}$ Pale green, $\lambda_{\max }=328 \mathrm{~nm}$. ${ }^{n}$ Pale green, $\lambda_{\max }=328 \mathrm{~nm}$. ${ }^{o}$ From Ref. 26 but shifted $0.08 \mathrm{~V}$ because of solvent change. ${ }^{p}$ Monitored by linear sweep voltammetry. ${ }^{a} E_{\text {ox }, p}=0.20 \mathrm{~V}$ vs. SCE at $v=1 \mathrm{~V} \mathrm{~s}^{-1}, C_{\mathrm{o}}=1.6 \mathrm{mM}, k_{\text {DIM }}$ assumed to be equal to $10^{9} \mathrm{M}^{-1} \mathrm{~s}^{-1}$. Kinetic shift in a DIM1 mechanism $=0.063 \mathrm{~V}$. $E_{\text {ox,p }}=0.274 \mathrm{~V}$ vs. SCE at $v=1 \mathrm{~V} \mathrm{~s}^{-1}, C_{\mathrm{o}}=0.84 \mathrm{mM}, k_{\text {DIM }}$ assumed to be equal to $10^{9} \mathrm{M}^{-1} \mathrm{~s}^{-1}$. Kinetic shift in a DIM1 mechanism $=0.058 \mathrm{~V}$. ${ }^{s}$ Red, $\lambda_{\max }=500 \mathrm{~nm}$. ${ }^{t}$ Monitored by ${ }^{1} \mathrm{H}$ NMR. ${ }^{4}$ From Ref. $4, \mathrm{pp} .47$ and 62 and shifted a further $0.08 \mathrm{~V}$ because of solvent change.

of similar $E_{\mathrm{Nu} / \mathrm{Nu}^{-}}^{\circ}$ values, or expressed differently, the energy of the initial state is the same. In contrast, the energy of the final state (substitution product + leaving group) is dependent on the energy of the new bond formed. Unfortunately, the differences in the strength of carbon-sulfur, carbon-carbon and carbon-oxygen bonds $^{31}$ are too small to conclude for certain whether a relationship between the development in $\Delta G_{\text {Sta }}$ and the $\mathrm{C}-\mathrm{Nu}$ bond strength is present.

In principle, all substitution reactions studied herein follow the inner-sphere ET mechanism with $\Delta G_{\mathrm{Sta}}>4 \mathrm{~kJ} \mathrm{~mol}^{-1}$. Previous studies employing stereochemical probes have shown that even a modest stabilisation of ca. $10 \mathrm{~kJ} \mathrm{~mol}^{-1}$ (or $k_{\mathrm{SUB}} / k_{\mathrm{ET}} \approx 100$ ) should be sufficient to prevent the formation of radical intermediates..$^{9,19,22,32,33}$ At that point, bond formation between the electron donor and the electrophile is so developed in the TS that the reaction proceeds by inversion at the central carbon and not by racemisation as seen for outer-sphere ET. In this sense, substitution reactions may be classified as $\mathrm{S}_{\mathrm{N}} 2$ processes when $k_{\mathrm{SUB}} / k_{\mathrm{ET}}>100$ or $\Delta G_{\mathrm{Sta}}>10 \mathrm{~kJ} \mathrm{~mol}^{-1}$. According to Figs. 1 and 2, this implies that the $\mathrm{S}_{\mathrm{N}} 2$ mechanism is expected to prevail for benzyl chloride when it is involved in reactions with nucleophiles of $E_{\mathrm{Nu} / \mathrm{Nu}^{-}}^{\circ}>-1.4 \mathrm{~V}$ vs. $\mathrm{SCE}$; a result in line with the conclusions presented in Ref. 21. Note that no specific steric effects are taken into consideration in the above discussion since benzyl chlor- ide essentially has no steric constraints. However, in particular cases this is not completely correct as illustrated by the results obtained for the nucleophiles 9-tertbutylfluorenide and fluorenide (entries 1 and 2, Table 4), where the latter has a higher reactivity as expected due to its much less sterically hindered nature and despite its less negative $E_{\mathrm{Nu} / \mathrm{Nu}^{\circ}}^{\circ}$ value.

The main advantage of the $k_{\mathrm{SUB}} / k_{\mathrm{ET}}$ approach is that it gives a quantitative measure of the electronic interaction in the TS and provides a description of substitution processes even if they appear to be alike at first glance from a stereochemical point of view. In this respect, the approach is also a better tool than the use of activation entropies $\Delta S^{\ddagger}{ }^{22,27}$ For inner-sphere ET the geometrical requirements of the TS are stricter compared with outer-sphere ET and more negative $\Delta S^{\ddagger}$ values are expected. However, the differences in $\Delta S^{\ddagger}$ vanish as $\Delta G_{\mathrm{Sta}}>10 \mathrm{~kJ} \mathrm{~mol}^{-1}$ and a detailed description of innersphere ET reactions can therefore not be obtained by this procedure.

Once a ranking of nucleophiles in terms of $k_{\mathrm{SUB}} / k_{\mathrm{ET}}$ has been accomplished as in the reaction of benzyl chloride, it becomes possible to predict when to expect inversion or partial racemisation in substitution reactions of these nucleophiles with other electrophiles. We propose that the ranking of nucleophiles presented above is valid also for other primary electrophiles although the absolute $\Delta G_{\text {Sta }}$ scale will be different. For instance, if 4-cyano- 
benzyl chloride with its higher reduction potential were used as the electrophile rather than benzyl chloride the electron-accepting ability would be increased while leaving the steric conditions at the electrophilic centre essentially unchanged. According to the free energy plots in Figs. 1 and 2, both the standard ET and the substitution reaction would then be expected to proceed faster with the latter process exhibiting a somewhat weaker potential dependence. Thus, the $k_{\mathrm{SUB}} / k_{\mathrm{ET}}$ ratio and $\Delta G_{\mathrm{Sta}}$ for a given nucleophile should diminish and substitution reactions involving nucleophiles with $E_{\mathrm{Nu}}^{\circ} / \mathrm{Nu}^{-}<-1.4 \mathrm{~V}$ vs. SCE would certainly be expected to have $k_{\mathrm{SUB}} / k_{\mathrm{ET}}<100$ for which partial racemisation takes place. A similar effect should be observed if a better leaving group such as bromide rather than chloride were introduced at the electrophilic centre.

If the electrophile becomes more sterically hindered than benzyl chloride, the steric conditions at the nucleophilic site are obviously going to play a much larger role and deviations from the general ranking listed above are expected. Some indications of how the $k_{\mathrm{SUB}} / k_{\mathrm{ET}}$ and $\Delta G_{\text {Sta }}$ values are affected when benzyl chloride is $\alpha$-substitued by alkyl groups may be found in a previous study carried out in $N, N$-dimethylformamide. ${ }^{27}$ While $k_{\mathrm{ET}}$ is affected only to a minor extent, $k_{\mathrm{SUB}}$ decreases substantially because a close approach of the nucleophile to the electrophile becomes difficult and in some cases even is prevented. The result is a large decrease of the $k_{\mathrm{SUB}} / k_{\mathrm{ET}}$ ratio. For instance, in the reaction of the anion of 1,4-dihydro-4-methoxycarbonyl-1-methylpyridine $\left(E_{\mathrm{Nu}^{\cdot} / \mathrm{Nu}^{-}}^{\circ}=-1.530 \mathrm{~V}\right.$ vs. SCE in $N, N$-dimethylformamide) $k_{\mathrm{SUB}} / k_{\mathrm{ET}}$ decreases from 83 to 0.8 going from benzyl chloride to (1-chloro-2,2-dimethylpropyl)benzene as the electrophile. ${ }^{27}$ Stereochemically, the former reaction is predicted to proceed by nearly complete inversion, while the latter should be characterised by racemisation. A rough estimate of the potential, at which $k_{\mathrm{SUB}} / k_{\mathrm{ET}}=$ 100 and changeover in mechanism occurs for (1-chloro2,2-dimethylpropyl)benzene, is $E_{\mathrm{Nu}^{\circ} / \mathrm{Nu}^{-}}^{\circ}=-1.0 \mathrm{~V}$ vs. SCE, a value higher by $0.4 \mathrm{~V}$ compared with the benzyl chloride system. On the other hand, if $E_{\mathrm{Nu}}^{\circ} / \mathrm{Nu}^{\prime}$ - becomes too high, the inner-sphere ET is not expected to occur at all for sterically hindered compounds since the substitution rate simply becomes too small. Elimination and $\mathrm{S}_{\mathrm{N}}$ 1-like reactions then provide alternative pathways. In the rate-controlling first step of the $S_{N} 1$ reaction the electrophile is dissociated to yield a carbonium ion stabilised by the electron-donating alkyl groups. In this manner, the electron-accepting ability is increased along with a release of the steric hindrance at the electrophilic centre and the attack of the nucleophile becomes possible in the second step.

\section{Experimental}

Reagents. The supporting electrolyte, $\mathrm{Bu}_{4} \mathrm{NBF}_{4}$, was prepared by standard procedures. Acetonitrile was distilled from $\mathrm{P}_{2} \mathrm{O}_{5}$ and subsequently $\mathrm{K}_{2} \mathrm{CO}_{3}$. Just prior to use it was dried through a column containing activated alumina. DMSO (Aldrich) was stored under nitrogen (Sure Seal bottles) and used without further purification. All handling of DMSO was performed on a vacuum line using normal syringe techniques. Benzyl chloride, aromatic mediators, tetrabutylammonium hydroxide $(40 \%$ $\mathrm{w} / \mathrm{w})$, tetrabutylammonium cyanide and most of the precursors of the nucleophiles (fluorene, $p$-methoxythiophenol, $p$-nitrothiophenol, thiophenol, phenol, 1-naphthol, 2-naphthol) were commercially available and used as received. The preparation of 4-methoxycarbonyl-1methylpyridinium perchlorate, 1-methyl-2,4,6-triphenylpyridinium perchlorate and 2,4,6-triphenylthiopyrylium perchlorate has been described previously. ${ }^{34}$ The corresponding nucleophiles were generated during cyclic voltammetry by a two step reversible reduction of the cations. 9-tert-Butylfluorene was synthesised as described in Ref. 24. Most of the anionic nucleophiles in DMSO were prepared by deprotonating $\mathrm{Nu}-\mathrm{H}$ with the base dimsylpotassium $\left(\mathrm{CH}_{3} \mathrm{SOCH}_{2} \mathrm{~K}\right)$ using the procedure of Olmstead et al. ${ }^{35}$ In acetonitrile, fluorenide was also generated electrochemically by reduction of 9-phenoxyfluorene. 4-Nitrothiophenolate in DMSO and all 4-substituted thiophenolates in acetonitrile were electrosynthesised by reduction of the corresponding bis(4substituted phenyl) disulfides. ${ }^{36}$ The parent compounds were prepared according to Drabowicz and Mikolajczyk. ${ }^{37}$

Instrumentation. NMR spectra were recorded on a Varian Gemini $200 \mathrm{MHz}$ spectrometer. The electrochemical equipment and data handling procedures have been described previously. ${ }^{38}$ A description of the electrochemical stopped-flow and dip-probe systems may be found in Ref. 39.

Procedures. Most of the anionic nucleophiles exhibit irreversible oxidation waves during cyclic voltammetry, even at scan rates as high as $100 \mathrm{~V} \mathrm{~s}^{-1}$. The irreversible peak oxidation potentials were measured relative to the ferrocenium/ferrocene redox pair, the standard potential of which is +0.410 and $+0.430 \mathrm{~V}$ vs. SCE in acetonitrile and DMSO, respectively. Previous studies of 9-substituted fluorenides have shown that the electrode reaction follows a DIM1 mechanism, in which the dimerisation of the radicals formed after oxidation of the anionic substrate at the electrode proceeds at a rate close to the diffusion-controlled limit. The only exception is when the substituent is large and bulky such as tert-butyl. ${ }^{24}$ In the present study the following slopes were found for almost all of the nucleophiles investigated in support of the DIM1 mechanism: ${ }^{40} \mathrm{~d} E_{\text {ox,p }} / \mathrm{d} \log v \approx 20 \mathrm{mV}$ and $\mathrm{d} E_{\text {ox,p }} / \mathrm{d} \log C_{\mathrm{o}} \approx-20 \mathrm{mV}$, where $E_{\text {ox,p }}$ is the irreversible peak oxidation potential, $v$ is the sweep rate and $C_{\mathrm{o}}$ the concentration of the nucleophile. In the case of diethyl methylmalonate anion in DMSO, however, the two slopes obtained ( 28 and $0 \mathrm{mV}$, respectively) were very different from the above values and the nucleophile was 
not included in Table 4. The oxidation peak potentials were converted to standard potentials by inserting the experimental parameters into eqn. (7). ${ }^{41}$

$E_{\mathrm{Nu} / \mathrm{Nu}}^{\circ}=E_{\mathrm{ox}, \mathrm{p}}-\frac{R T}{F} 0.902+\frac{R T}{3 F} \ln \left(\frac{2 R T k_{\mathrm{DIM}} C_{\mathrm{o}}}{3 F v}\right)$

The rate constant of dimerisation $k_{\text {DIM }}$ was assumed in general to be $5 \times 10^{9} \mathrm{M}^{-1} \mathrm{~s}^{-1}$ and $10^{9} \mathrm{M}^{-1} \mathrm{~s}^{-1}$ for acetonitrile and DMSO, respectively. ${ }^{24,25}$

The methods used for measuring $k_{\mathrm{ET}}$ have been described previously. ${ }^{38}$ As regards the determination of $k_{\text {SUB }}$, cyclic voltammetry was used for the first three nucleophiles listed in Table $3 .^{7}$ When the anionic nucleophiles were coloured, stopped-flow or dip-probe experiments were normally employed..$^{39,42}$ The reaction of non-coloured nucleophiles (deprotonated 2-methylcyclohexane-1,3-dione and 2-benzoylpropiophenone) was monitored by measuring the peak oxidation current in linear sweep voltammetry at a fixed sweep rate. All experiments were conducted with an excess of benzyl chloride in order to achieve pseudo first order conditions.

${ }^{1} \mathrm{H}$ NMR spectroscopy was used to monitor the slow reactions of $\mathrm{HO}^{-}$and $\mathrm{CN}^{-}$with benzyl chloride. The reaction between $\mathrm{HO}^{-}$and benzyl chloride was carried out in an NMR-tube by mixing $400 \mathrm{mM} \mathrm{Bu}_{4} \mathrm{~N}^{+} \mathrm{OH}^{-}$ and $40 \mathrm{mM}$ benzyl chloride in deuteriated solvents of acetonitrile or DMSO. The disappearance of the peak at $\delta_{\mathrm{H}}=4.76\left(2 \mathrm{H}, \mathrm{s}, \mathrm{PhCH} \mathrm{H}_{2} \mathrm{Cl}\right)$ and appearance of the new peak at $\delta_{\mathrm{H}}=4.66\left(2 \mathrm{H}, \mathrm{s}, \mathrm{PhCH}_{2} \mathrm{OH}\right)$ were followed for $48 \mathrm{~h}$. For the reaction between $\mathrm{CN}^{-}$and benzyl chloride in deuteriated acetonitrile, $400 \mathrm{mM} \mathrm{Bu} \mathrm{N}^{+} \mathrm{CN}^{-}$was mixed with $40 \mathrm{mM}$ benzyl chloride. The disappearance of the peak at $\delta_{\mathrm{H}}=4.76\left(2 \mathrm{H}, \mathrm{s}, \mathrm{PhCH} \mathrm{H}_{2} \mathrm{Cl}\right)$ and appearance of the new peak at $\delta_{\mathrm{H}}=3.99\left(2 \mathrm{H}, \mathrm{s}, \mathrm{PhCH}_{2} \mathrm{CN}\right)$ were followed. In DMSO the reaction was faster and carried out under second order conditions by mixing $40 \mathrm{mM}$ of both reactants.

\section{References}

1. Kornblum, N. Angew. Chem. 87 (1975) 797.

2. Pross, A. Acc. Chem. Res. 18 (1985) 212.

3. Ashby, E. C. Acc. Chem. Res. 21 (1988) 414.

4. Eberson, L. Electron Transfer Reactions in Organic Chemistry, Springer-Verlag, Heidelberg 1987.

5. Eberson, L. Acta Chem. Scand., Ser. B 36 (1982) 533.

6. Eberson, L. Acta Chem. Scand., Ser. B 38 (1984) 439.

7. Lund, T. and Lund, H. Acta Chem. Scand., Ser. B 40 (1986) 470.

8. Savéant, J.-M. Adv. Phys. Org. Chem. 26 (1990) 1.

9. Lund, H., Daasbjerg, K., Lund, T. and Pedersen, S. U. Acc. Chem. Res. 28 (1995) 313 and references cited therein.
10. Lund, H., Daasbjerg, K., Lund, T. and Pedersen, S. U. Macromol. Symp. 134 (1998) 73.

11. Eberson, L. and Shaik, S. S. J. Am.Chem. Soc. 112 (1990) 4484.

12. Shaik, S., Danovich, D., Sastry, G. N., Ayala, P. Y. and Schlegel, H. B. J. Am. Chem. Soc. 119 (1997) 9237.

13. Sastry, G. N. and Shaik, S. S. J. Am.Chem. Soc. 120 (1998) 2131.

14. Marcus, R. A. J. Phys. Chem. A 101 (1997) 4072.

15. Marcus, R. A. J. Chem. Phys. 24 (1956) 966.

16. Marcus, R. A. J. Chem. Phys. 26 (1957) 867.

17. Savéant, J.-M. J. Am. Chem. Soc. 109 (1987) 6788.

18. Andrieux, C. P., Le Gorande, A. and Savéant, J.-M. J. Am. Chem. Soc. 114 (1992) 6892.

19. Daasbjerg, K., Pedersen, S. U. and Lund, H. Acta Chem. Scand. 43 (1989) 876.

20. Daasbjerg, K. and Lund, H. Acta Chem. Scand. 47 (1993) 597.

21. Niyazymbetov, M. E., Rongfeng, Z. and Evans, D. H. J. Chem. Soc., Perkin Trans. 2 (1996) 1957.

22. Daasbjerg, K., Pedersen, S. U. and Lund, H. Acta Chem. Scand. 45 (1991) 424.

23. Jakobsen, S., Jensen, H., Pedersen, S. U. and Daasbjerg, K. J. Phys. Chem. A 103 (1999) 4141.

24. Lund, T. and Pedersen, S. U. J. Electroanal. Chem. 362 (1993) 109.

25. Andrieux, C. P.. Hapiot. P.. Pinson. J. and Savéant. J.-M J. Am. Chem. Soc, 115 (1993) 7783.

26. Hapiot, P., Pinson, J. and Yousfi, N. New J. Chem. 16 (1992) 877.

27. Balslev, H., Daasbjerg, K. and Lund, H. Acta Chem. Scand. 47 (1993) 1221.

28. Daasbjerg, K. and Christensen, T. B. Acta Chem. Scand. 49 (1995) 128.

29. Sørensen, H. S. and Daasbjerg, K. Acta Chem. Scand. 52 (1998) 51

30. Jensen, H. and Daasbjerg, K. Acta Chem. Scand. 52 (1998) 1151.

31. Handbook of Chemistry and Physics, 72nd edn., Lide, D. R., Ed., CRC Press, Boca Raton 1991.

32. Daasbjerg, K., Lund, T. and Lund, H. Tetrahedron Lett. 30 (1989) 493.

33. Daasbjerg, K. and Lund, H. Acta Chem. Scand. 50 (1996) 299.

34. Kristensen, J. S. and Lund, H. Acta Chem. Scand. 44 (1990) 524

35. Olmstead, W. N., Margolin, Z. and Bordwell, F. G. J. Org. Chem. 45 (1980) 3295.

36. Christensen, T. B. and Daasbjerg, K. Acta Chem. Scand. 51 (1997) 307.

37. Drabowicz, J. and Mikolajczyk, M. Synthesis (1980) 32 and references cited therein.

38. Pedersen, S. U. and Svensmark, B. Acta Chem. Scand., Ser. A 40 (1986) 607.

39. Pedersen, S. U., Christensen, T. B., Thomasen, T. and Daasbjerg, K. J. Electroanal. Chem. 454 (1998) 123.

40. Andrieux, C. P., Nadjo, L. and Savéant, J. M. J. Electroanal. Chem. 42 (1973) 223.

41. Bard, A. J. and Faulkner, L. R. Electrochemical Methods Fundamentals and Applications, Wiley, New York 1980.

42. Pedersen, S. U., Lund, T., Daasbjerg, K., Pop, M., Fussing, I. and Lund, H. Acta Chem. Scand. 52 (1998) 657.

Received January 25, 1999. 